\title{
Clinical observation of different treatment strategies in pregnant women with COVID-19: a retrospective study
}

\section{Gang Lei}

Department of Obstetrics and Gynecology, Central hospital of Wuhan, affiliated to Huazhong University of Science and Technology, Wuhan 430014, China

Jinghua Tian

Department of Obstetrics, Renmin hospital of Wuhan university, high-tech development zone of Donghu, Wuhan, China

\section{Shuangqin Peng}

Department of Pediatrics, Maternal and Child hospital of Hubei province, Wuhan, China

\section{Xiaoji Hu}

Department of Obstetrics and Gynecology, Central hospital of Wuhan, affiliated to Huazhong University of Science and Technology, Wuhan 430014, China

\section{Pei Zhang}

Department of Obstetrics and Gynecology, Central hospital of Wuhan, affiliated to Huazhong University of Science and Technology, Wuhan 430014, China

\section{Wen-ning Wu}

Department of Pharmacology, School of Basic Medical Sciences, Anhui Medical University, Hefei, China

\section{Guoping Xiong ( $\sim$ hyh01201@163.com)}

Department of Obstetrics and Gynecology, Central hospital of Wuhan, affiliated to Huazhong University of Science and Technology, Wuhan 430014, China

\section{Research Article}

Keywords: COVID-19, SARS-COV-2, pregnant women, spontaneous miscarriage, fetal malformation

Posted Date: June 4th, 2020

DOI: https://doi.org/10.21203/rs.3.rs-33186/v1

License: (c) (i) This work is licensed under a Creative Commons Attribution 4.0 International License. Read Full License 


\section{Abstract}

Objective: this study aimed to clarify the clinical characteristics, obstetrical and fetal outcomes of patients with Corona Virus Disease 2019 (COVID-19) in different stage during pregnancy.

Methods: 13 pregnant women with COVID-19 were admitted to Wuhan central hospital and Renmin hospital of Wuhan university between Jan 20 and march 20, 2020, including four patients in first and second trimester demanding for pregnancy termination, seven in first and second trimester and two in third trimester keeping pregnancy. The two groups' clinical characteristics, treatment and maternal and fetal outcomes were observed and analyzed.

Results: Most common clinical manifestation were fever and cough. Among the patients keeping pregnancy, one had a spontaneous miscarriage and fetal malformation was found in another one. Two patients who had a vaginal delivery presented good maternal and neonatal outcomes. All patients showed a good recovery.

Conclusion: SARS-COV-2 infection could cause spontaneous miscarriage and fetal malformation in early pregnancy.

\section{Introduction}

Since January 2020, COVID-2019 has caused a worldwide epidemic, which affected more than eighty thousand people and led to the death of over four thousand people in china(1). Previous studies in pregnant women with SARS have

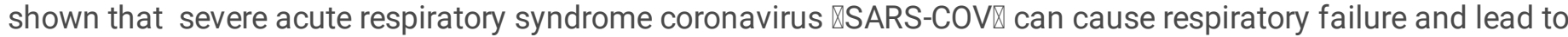
adverse pregnancy and neonatal outcomes, such as spontaneous miscarriage, premature delivery and fetal growth restriction(2). Recent studies had shown that the outcomes of pregnant women with COVID-19 in third trimester are satisfactory $(3,4)$. However, the epidemiology and clinical features in early pregnancy by COVID-19 is scarcely reported. Here, we present the information of 13 pregnant women infected SARS-cov-2 including epidemiology, clinical manifestations $₫$ laboratory results, follow-visit outcome, which could provide some initial evidence for guiding the treatment of early pregnant women with COVID-19.

\section{Methods}

\section{Study design and participants}

The central hospital of Wuhan and Renmin hospital of Wuhan university were designated by government to receive and treat pregnant patients infected SARS-COV-2. All the pregnant patients in these two hospitals met the criteria which were used to diagnose with SARS-COV-2 infection by WHO interim guidance(5).In this retrospective study, thirteen pregnant patients from these two hospitals were recruited between Jan 20 and March 20, 2020. The mean age of the patients is $30.6 \pm 4.8$ years old (range from 24 to 40 years old). We obtained epidemiological, demographic and followup visit data, laboratory results, clinical management, maternal and fetal outcomes from patients' medical records. This study was approved by the ethics committee of the central hospital of Wuhan and Renmin hospital of Wuhan university. And the written informed consent was obtained from the patients for the publication of individual information when data were collected retrospectively.

\section{Procedure}

The epidemic data and follow-visit information were obtained from medical records or telephone interview to patients themselves. If the data were missing from the records or the clarification was needed, we would directly communicate with attending doctors and other health providers. 
Because it is unclear how the SARS-COV-2 affected maternal and neonatal outcomes in early pregnancy, we agreed to the demands of four pregnant women to terminate pregnancy in first and second trimester. Other nine pregnant women preferred to keep pregnancy until full term, including seven in first and second trimester and two in third trimester. In addition, nine patients keeping pregnancy were given numbers in order to describe follow-visit information well (Table 3). All pregnancies in the first trimester were identified by pregnancy test and uterus ultrasound examination. Blood examination including leukocyte, lymphocyte and platelet counts, hemoglobin and c-reactive protein level were routinely examined weekly. computed tomography $₫ \mathrm{CT}$ \examination were performed for the pregnant women who terminate pregnancy once every week in order to observing the image changes, and information of fetal growth in nontermination group was assessed by obstetrical ultrasound scan once every two weeks. Based on the diagnosis and treatment protocols for pneumonia caused by SARS-COV-2 published by the National Health Commission of the People's Republic of China (trial version 7)(6), all pregnant patients were managed jointly in accordance with the guidelines and regulations by the respiratory physicians, disease specialists and obstetricians. They received empirical antibiotic treatment, oxygen and symptomatic support therapy. Chinese medicine was administrated to the pregnant patients who kept pregnancy, while antiviral treatment was given to those who demanded to terminate pregnancy.

Nasopharyngeal swab specimens from upper respiratory tract in all pregnant patients were sent to designated laboratory by government for SARS-COV-2 quantification via RT-PCR testing(7). The levels of immunoglobulin M and immunoglobulin $\mathrm{G}$ antibodies in the serum of pregnant patients infected SARS-cov-2 were detected by ELISA kit. Other respiratory virus, including influenza $A$ virus, influenza $B$ virus, adenovirus, parainfluenza virus and respiratory syncytial virus, were tested by real-time RT-PCR. mycoplasma pneumoniae and chlamydia pneumoniae, which children are more susceptible to, were also monitored.

\section{Statistical Analysis}

Statistical analysis was performed using IBM SPSS 20.0. Continuous variables are directly expressed as ranges, and categorical variables are expressed as numbers and percentages. The data are presented as means \pm SD.

\section{Results}

13 pregnant patients with COVID-19 『including four health care workers and five others infected by contacting their families or covid-19 patients, 4 patients with no explicit contacting history just performing obstetrical examinations in hospital during covid-19 outbreak, had a positive result for SARS-COV-2 RT-PCR test at the time of admission. The mean gestational age of the pregnant women who requested to terminate pregnancy is $13.3 \pm 5.4$ weeks (range from 5.1 weeks to 21.5 weeks), and that is $17 \pm 9.2$ weeks (range from 5.1 weeks to 31.5 weeks) in those pregnant patients who kept pregnancy (Table 1). Except one patient with hyperthyroidism which were controlled with drugs well, other patients had no underlying medical diseases. Among the 13 patients, most common clinical manifestations were fever (84.6\%), cough $(61.5 \%)$, secondly fatigue (30\%) and shortness of breath (23\%). One patient $(7.7 \%)$ had diarrhea with transit disappear of smell. Other 5 patients $₫ 38.5 \% \bigotimes$ had no clinical symptoms of COVID-19 pneumonia. In the patients with pregnancy termination, there was no recurrent fever, or aggravative infection symptoms after surgery. The symptoms in all patients completely disappeared 7 days after SARS-COV-2 infection.

As shown in Table 2, only one patient (7.7\%) had lower leukocyte count after pregnancy termination surgery. Lymphopenia (<1.0) was observed in five patients (38.5\%), and subsequently developed to normal. The level of Creactive protein is increased in three patients (23.1\%) keeping pregnancy. Only one patient (7.7\%) had a slight increase in the levels of liver alanine aminotransferase and aspartate aminotransferase at admission. After treatment, leukocyte counts, lymphocyte counts, and c-reactive protein levels returned to normal state in all patients. The abortion patients have no fever and infection. The patients could not discharge from the hospital until they have twice SARS-COV-2 
negative tests in row. The course of disease in patients keeping pregnancy is $28.4 \pm 9.0$ days, while that is $10.7 \pm 4.5$ days in patients with pregnancy termination, indicating that termination pregnancy reduced the course of disease in patients with COVID-19. 10 patients (76.9\%) still have positive results with Ig-G antibody and 4 patients (30.7\%) with Ig-M antibody against SARS-COV-2. All patients had no infection with other respiratory virus. Some CT imagines similar to atypical pneumonia, such as "crazy paving sign" "segmental pulmonary consolidation" and "ground glass shadow",

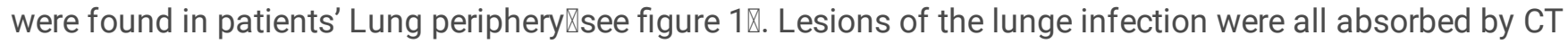
examination at time of discharge.

All patients received combination therapy(8)『including empirical antibiotic treatment, oxygen and symptomatic support therapy. The antiviral treatment was only given to those who demanded to terminate pregnancy. The drugs were used

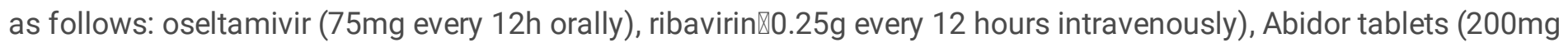
three times a day orally). Traditional Chinese medicine, such as Jinyebaidu granules and Lianhuaqingwen capsules, were also administrated to patients keeping pregnancy.

As for maternal and neonatal outcomes, all patients have no intensive care unit admissions during the study period. They were allowed to discharge with following criteria: body temperature returned to normal for more than 3 days, respiratory symptoms improved significantly, pulmonary imagine showed a significant improvement and twice negative nucleic test of SARS-covs-2 in a row. Patient one, whose gestational age was 36 days, had positive pregnancy tests during hospital admission, and exclude a fleshy tissue from the vagina 3 days later. Serial serum human chorionic gonadotrophins rapidly decreased and she was considered to have a very early pregnancy loss. we also investigated the current situation of pregnant patients keeping pregnancy by a telephone follow-up visit. Maternal and fetal outcomes were presented as follow (table 3). All patients were quarantined in designated place for 28 days after discharge, and they have a negative nucleic test of SARS-COV-2 after quarantining. Then, they were followed for 28 to 78 days. We found that two patients were carried by induced abortion, one of whom conducted for social reasons at 13 weeks. Another patient's fetal was found to have multiple heart and kidney abnormalities. A study was under way on whether abnormal ultrasound signs is related to SARS-COV-2 infection. There were no abnormalities presented in four pregnant women with selective examination such as routine labor examination, systematic ultrasound screening, Non-

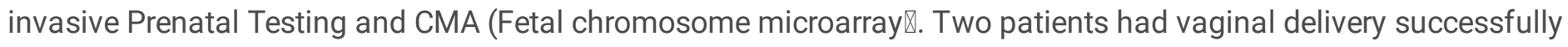
two neonates looked vital without respiratory symptoms or fever and tested negative results for SARS-COV-2 infection.

\section{Discussion}

This is the first descriptive study that shows the clinical characteristics and outcomes of pregnant patients with COVID2019 in first and second trimester. From our knowledge, physiologic adaptive changes apparently happened during late pregnancy, such as diaphragm elevation, increased oxygen consumption and edema of respiratory tract mucosa, which made them intolerant to hypoxia(9). It happened in SARS-COV infected women in 2003 associated with high maternal morbidity and mortality and high incidences of spontaneous miscarriage, preterm delivery, and IUGR(8). Comparing to this, good outcomes for both mother and infant infected with covid-19 in late pregnancy presented in previous studies $(3,4,10)$. Considering the good maternal and fetal results in term pregnancy may attributed to conducting delivery or Caesarean section rapidly. In our study, we have presented that 13 patients far from term pregnancy seemed to achieved a good outcome regarding maternal infections and the incidence of adverse neonatal outcomes appeared similar to normal pregnancy.

In our study $₫$ one patient (11.1\%) had spontaneous miscarriage in her 5 gestational weeks, which was the same rate as $10 \%$ to $20 \%$, widely reported in early pregnancy loss rate(11). Our data showed that the most common onset symptoms for the pregnant women with COVID-19 pneumonia were fever and cough, Because of early pregnant characteristics, 
non-specific symptoms such as fatigue appeared more apparently than non-pregnant women. Lymphocyte count reduction rate $(38.5 \%)$ was similar as previous studies $(8,9)$ at laboratory examinations. C-reactive protein levels were increased and leucocyte counts were normal in most of the thirteen pregnant patients.

Ribavirin is a commonly used first-line medication for the management of SARS in Hong Kong. Ribavirin has been proved effective in SARS(2). But the drug has been shown to cause teratogenic effects in animals, such as a significant embryocidal effect and a cause of spontaneous miscarriage $(12,13)$. Some animal studies had also showed that large doses of glucocorticoids can cause deformities in embryos. Therefore, we practiced a combination therapy with Ribavirin, glucocorticoids in determination group \while selective therapy to patients keeping pregnancy. However, all patients achieved good recovery with no difference in terms of maternal outcomes. Interestingly $₫$ the time interval from admission to discharge in patients with termination pregnancy is seemed to be significantly shorter than that in patients keeping pregnancy $(10.7 \pm 4.5$ vs $28.4 \pm 9.0 p<0.05)$.

There was a case-report showing that vertical transmission of SARS-COV-2 infection may harms the fetus during the acute phase(14). In our study, nine patients keeping pregnancy were given numbers (table 3) and followed up. There was no abnormal fetal development in six patients (66.7\%) with serial obstetrical examination including two new-born neonates. But the system color ultrasound in patient 4 indicated multiple fetal malformations including heart and kidney malformations. Fetal outcomes of patient 1 and patient 4 suggested that the virus may directly cause fetal dysplasia due to vertical transmission in early pregnancy. However, further research is needed to determine whether the SARS-COV-2 can be transmitted vertically and affect the neonatal. In addition, there were still some limitations. First, the number of cases included in the study was too small. More infected pregnant women and comparative studies (e.g. cohorts, case-control) should be analyzed to get a more comprehended understanding of covid-19 in pregnancy. Second, due to the short time of outbreak, follow-up of infant outcomes should end up with the long-term outcomes and prognosis of the fetus after birth.

\section{Conclusions}

The clinical characteristic of these patients with covid-19 in first and second trimester are all mild and are similar to those reported by non-pregnant adults with COVID-19. Adverse neonatal outcomes such as spontaneous miscarriage and fetal malformation may happened in early pregnancy. Long-term outcomes and potential vertical transmission should be further studied in the future.

\section{Tables}


Table 1: maternal characteristics and clinic presentation of thirteen Pregnant Women With COVID-19

\begin{tabular}{|c|c|c|c|c|c|}
\hline \multirow{4}{*}{ characteristic } & \multirow{2}{*}{$\begin{array}{l}\text { All } \\
\text { patients } \\
\text { (num) }\end{array}$} & \multirow{2}{*}{$\begin{array}{l}\text { termination } \\
\text { group } \\
\text { (num) }\end{array}$} & \multicolumn{2}{|c|}{ non-termination group } & \multirow{4}{*}{ P or $\%$} \\
\hline & & & $\begin{array}{l}\text { The first and } \\
\text { second- }\end{array}$ & $\begin{array}{l}\text { The third trimester } \\
\text { (num) }\end{array}$ & \\
\hline & \multirow[t]{2}{*}{$n=13$} & \multirow[t]{2}{*}{$n=4$} & $\begin{array}{l}\text { trimester } \\
\text { (num) }\end{array}$ & \multirow[t]{2}{*}{$\mathrm{n}=2$} & \\
\hline & & & $\mathrm{n}=7$ & & \\
\hline \multirow[t]{2}{*}{ Age, mean (), range (years) } & & $30 \pm 5.4$ & \multirow{2}{*}{\multicolumn{2}{|c|}{$\begin{array}{l}31 \pm 4.8 \\
(24-40)\end{array}$}} & $P>0.05$ \\
\hline & & $(24-37)$ & & & \\
\hline \multirow{2}{*}{$\begin{array}{l}\text { Gestational week at admission, } \\
\text { mean (), range }\end{array}$} & & $13.3 \pm 5.4$ & \multirow{2}{*}{\multicolumn{2}{|c|}{$\begin{array}{l}17 \pm 9.2 \\
(5-31.5)\end{array}$}} & \multirow[t]{2}{*}{$P>0.05$} \\
\hline & & $(8-21)$ & & & \\
\hline Time Interval (day) & & $4-10$ & $2-7$ & & $P>0.05$ \\
\hline other conditions $^{a}$ & 1 & 1 & 0 & 0 & $(7.7 \%)$ \\
\hline Adverse abortion history ${ }^{b}$ & 1 & 1 & 0 & 0 & $(7.7 \%)$ \\
\hline Contact history of epidemic & 7 & 2 & 3 & 2 & $(53.8 \%)$ \\
\hline \multicolumn{6}{|l|}{ Symptoms with covid-19 } \\
\hline fever & 11 & 2 & 7 & 2 & $(84.6 \%)$ \\
\hline cough & 8 & 2 & 4 & 2 & $(61.5 \%)$ \\
\hline Short of breath & 3 & 1 & 1 & 1 & $(23 \%)$ \\
\hline diarrhea & 1 & 0 & 1 & 0 & $(7.6 \%)$ \\
\hline fatigue & 4 & 3 & 1 & 0 & $(30.8 \%)$ \\
\hline
\end{tabular}

a: one patient with hyperthyroidism which were controlled with drugs well. b: One patient had a history of missed abortion. Time interval: time interval between onset symptom and admission 
Table 2: Laboratory characteristics and treatment received

\begin{tabular}{|c|c|c|c|c|c|}
\hline \multirow{3}{*}{ Laboratory characteristics } & \multirow{3}{*}{$\begin{array}{l}\text { All } \\
\text { patients } \\
\text { (num) } \\
\mathrm{n}=13\end{array}$} & \multirow{3}{*}{$\begin{array}{l}\text { termination } \\
\text { group } \\
\text { (num) } n=4\end{array}$} & \multicolumn{2}{|c|}{ non-termination group } & \multirow{3}{*}{$\underset{\%}{P}$ or } \\
\hline & & & \multirow{2}{*}{$\begin{array}{l}\text { The first and } \\
\text { second trimester } \\
\text { (num) } n=7\end{array}$} & \multirow{2}{*}{$\begin{array}{l}\text { The third } \\
\text { trimester } \\
\text { (num) } n=2\end{array}$} & \\
\hline & & & & & \\
\hline \multicolumn{6}{|l|}{ Leukocytopenia } \\
\hline Before treatment & 2 & 0 & 1 & 1 & $15 \%$ \\
\hline After treatment & 1 & 1 & 0 & 0 & $7.7 \%$ \\
\hline \multicolumn{6}{|l|}{ Lymphopenia } \\
\hline Before treatment & 5 & 1 & 3 & 1 & $38.5 \%$ \\
\hline After treatment & 0 & 0 & 0 & 0 & 0 \\
\hline \multicolumn{6}{|l|}{ Elevated c-reactive protein } \\
\hline Before treatment & 3 & 0 & 3 & 0 & $23.1 \%$ \\
\hline After treatment & 0 & 0 & 0 & 0 & 0 \\
\hline \multirow{2}{*}{$\begin{array}{l}\text { Duration between admission and } \\
\text { the moment for twice negative tests }\end{array}$} & & $10.7 \pm 4.5$ & $28.4 \pm 9.0$ & & ${ }^{*} \mathrm{P}=$ \\
\hline & & & & & 0.02 \\
\hline \multicolumn{6}{|l|}{ Qualitative RT-PCR Result } \\
\hline $\begin{array}{l}\text { Positive for SARS -cov-2 before } \\
\text { treatment }\end{array}$ & 12 & 3 & 7 & 2 & $92.3 \%$ \\
\hline $\begin{array}{l}\text { Negative for SARS- cov- } 2 \text { after } \\
\text { treatment }\end{array}$ & 0 & 0 & 0 & 0 & 0 \\
\hline \multicolumn{6}{|l|}{ Qualitative antibody of SARS -cov-2 } \\
\hline Positive for lgG & 10 & 2 & 6 & 2 & $76.9 \%$ \\
\hline Positive for lgM & 4 & 2 & 2 & 0 & $30.7 \%$ \\
\hline \multicolumn{6}{|l|}{ Treatment for covid -19 } \\
\hline Oxygen support & 13 & 4 & 7 & 2 & $100 \%$ \\
\hline Antiviral therapy & 5 & 4 & 1 & 0 & $38.5 \%$ \\
\hline Antibiotic therapy & 13 & 4 & 7 & 2 & $100 \%$ \\
\hline Immunoglobulin therapy & 3 & 0 & 2 & 1 & $23.1 \%$ \\
\hline Chinese medicine & 11 & 4 & 5 & 2 & $84.6 \%$ \\
\hline
\end{tabular}

RT-PCR: reverse transcription-polymerase chain reaction. SARS-cov-2: severe acute respiratory syndrome coronavirus 2 . ${ }^{*} P<0.05$ : shows statistically significant difference. 
Table 3: maternal and fetal outcomes of nine patients keeping pregnancy

\begin{tabular}{|c|c|c|c|c|c|c|c|c|c|}
\hline \multirow{2}{*}{$\begin{array}{l}\text { Pregnancy } \\
\text { outcome }\end{array}$} & \multicolumn{9}{|l|}{ Patient } \\
\hline & 1 & 2 & 3 & 4 & 5 & 6 & 7 & 8 & 9 \\
\hline discharge & yes & yes & yes & yes & yes & yes & yes & yes & yes \\
\hline $\begin{array}{l}\text { Follow-up of } \\
\text { gestational } \\
\text { age }\end{array}$ & NA & 18 & 30 & NA & NA & $28+5$ & 34 & 39 & $39+3$ \\
\hline $\begin{array}{l}\text { Days of } \\
\text { quarantine } \\
\text { out of hos } \\
\text { pital }\end{array}$ & 28 & 28 & 28 & 28 & 28 & 28 & 28 & 28 & 28 \\
\hline $\begin{array}{l}\text { RT-PCR for } \\
\text { SARS-CoV-2 }\end{array}$ & प & प & ( & प & ( & प & ? & प & ૧ \\
\hline \multicolumn{10}{|l|}{ Negative (-) } \\
\hline $\begin{array}{l}\text { Days follow } \\
\text { up }\end{array}$ & 28 & 48 & 73 & 43 & 28 & 44 & 78 & 45 & 83 \\
\hline $\begin{array}{l}\text { Obstetrical } \\
\text { complication }\end{array}$ & no & no & no & no & no & No & no & no & no \\
\hline $\begin{array}{l}\text { Maternal } \\
\text { outcomes }\end{array}$ & yes & yes & yes & yes & yes & yes & yes & $\begin{array}{l}\text { Vaginal } \\
\text { delivery }\end{array}$ & $\begin{array}{l}\text { Vaginal } \\
\text { delivery }\end{array}$ \\
\hline $\begin{array}{l}\text { Neonatal } \\
\text { outcomes }\end{array}$ & Spontaneosmiscarriage & yes & yes & $\begin{array}{l}\text { Fetal } \\
\text { malf } \\
\text { ormation }\end{array}$ & $\begin{array}{l}\text { Induce } \\
\text { abortion }\end{array}$ & yes & yes & yes & yes \\
\hline
\end{tabular}

NA: not applicable

\section{Declarations}

\section{Acknowledgements}

This work was supported by grants from the National Natural Science Foundation of china(NSFC,No.81671327).

\section{Conflicts of interest}

We declare no conflict of interests.

\section{References}

1. Hui DS, E IA, Madani TA, Ntoumi F, Kock R, Dar O, et al. The continuing 2019-nCoV epidemic threat of novel coronaviruses to global health - The latest 2019 novel coronavirus outbreak in Wuhan, China. International journal of infectious diseases : IJID : official publication of the International Society for Infectious Diseases. 2020;91:2646.

2. Wong SF, Chow KM, Leung TN, Ng WF, Ng TK, Shek CC, et al. Pregnancy and perinatal outcomes of women with severe acute respiratory syndrome. American journal of obstetrics and gynecology. 2004;191(1):292-7.

3. Liu D, Li L, Wu X, Zheng D, Wang J, Yang L, et al. Pregnancy and Perinatal Outcomes of Women With Coronavirus Disease (COVID-19) Pneumonia: A Preliminary Analysis. AJR American journal of roentgenology. 2020:1-6. 
4. Yu N, Li W, Kang Q, Xiong Z, Wang S, Lin X, et al. Clinical features and obstetric and neonatal outcomes of pregnant patients with COVID-19 in Wuhan, China: a retrospective, single-centre, descriptive study. The Lancet Infectious diseases. 2020;20(5):559-64.

5. WHO. Novel coronavirus-China. World Health Organization. 2020.

6. NHCotPsRo C. Diagnosis and treatment protocols of pneumonia caused by a novel coronavirus (trial version 5). 2020.

7. Huang C, Wang Y, Li X, Ren L, Zhao J, Hu Y, et al. Clinical features of patients infected with 2019 novel coronavirus in Wuhan, China. Lancet. 2020;395(10223):497-506.

8. WHO. Clinical management of severe acute respiratory infection when Middle East respiratory syndrome coronavirus (MERS-CoV) infection is suspected: Interim guidance. World Health Organization. 2020.

9. Chen H, Guo J, Wang C, Luo F, Yu X, Zhang W, et al. Clinical characteristics and intrauterine vertical transmission potential of COVID-19 infection in nine pregnant women: a retrospective review of medical records. Lancet. 2020;395(10226):809-15.

10. Chen L, Li Q, Zheng D, Jiang H, Wei Y, Zou L, et al. Clinical Characteristics of Pregnant Women with Covid-19 in Wuhan, China. The New England journal of medicine. 2020.

11. Ng PC, So KW, Leung TF, Cheng FW, Lyon DJ, Wong W, et al. Infection control for SARS in a tertiary neonatal centre. Archives of disease in childhood Fetal and neonatal edition. 2003;88(5):F405-9.

12. Wilcox AJ, Weinberg CR, O'Connor JF, Baird DD, Schlatterer JP, Canfield RE, et al. Incidence of early loss of pregnancy. The New England journal of medicine. 1988;319(4):189-94.

13. Kochhar DM, Penner JD, Knudsen TB. Embryotoxic, teratogenic, and metabolic effects of ribavirin in mice. Toxicology and applied pharmacology. 1980;52(1):99-112.

14. Zhu H, Wang L, Fang C, Peng S, Zhang L, Chang G, et al. Clinical analysis of 10 neonates born to mothers with 2019-nCoV pneumonia. Translational pediatrics. 2020;9(1):51-60.

\section{Figures}



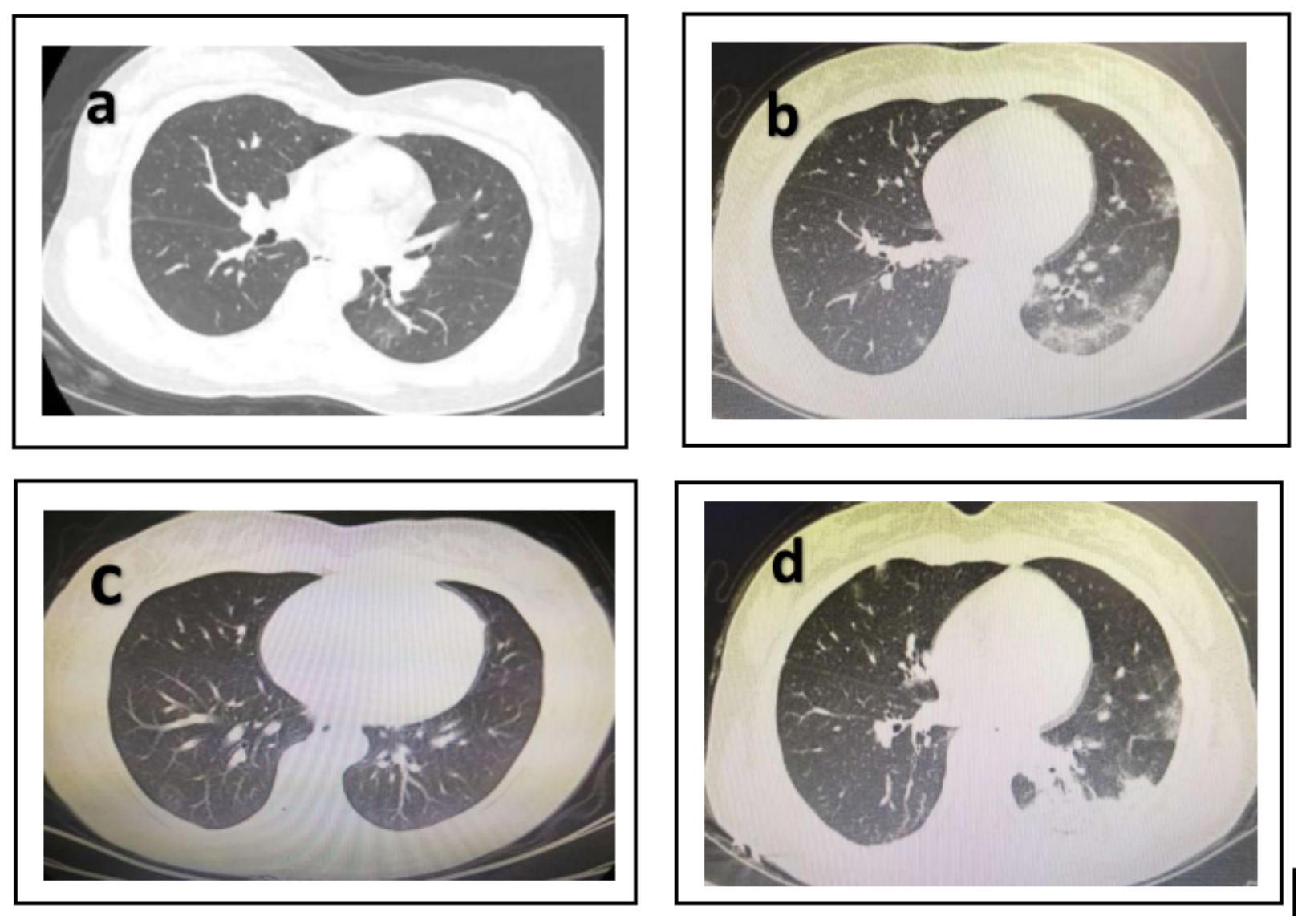

Figure 1

Chest CT scans of four patients demanding for pregnancy termination. Patient a and c: bilateral clear lung fields with no obvious ground-glass opacities. Patient b: subpleural and peribronchial patchy consolidation in the left lung. patient d:left-sided subpleural patchy ground-glass opacity seemed as "crazy paving sign" 